\title{
Comparison between isolated serial clinical examination and computed tomography for stab wounds in the anterior abdominal wall
}

\section{Comparação entre exame clínico seriado isolado e tomografia computadorizada nos ferimentos por arma branca na parede anterior do abdome}

Ricardo Breigeiron, TCBC-RS ${ }^{1,2}$; Tiago Cataldo Breitenbach ${ }^{1}$; Lucas Adalberto Geraldi Zanini ${ }^{1}$; Carlos Otavio Corso, TCBC-RS ${ }^{1,2}$,

\begin{abstract}
A B S T R A C T
Objective: to compare abdominal computer tomography (CT) with isolated serial clinical exam (SCE) in the management of anterior abdominal stab wounds. Methods: randomized prospective study performed at Hospital de Pronto Socorro de Porto Alegre involving patients with anterior abdominal stab wounds without indication of immediate laparotomy; patients were divided in two groups: CT group and SCE group, In the SCE group, patients were followed up with serial clinical exam every 6 hours, Patients of CT group were submitted to abdominal computer tomography after initial evaluation. Results: 66 patients were studied and 33 were included in each group, Of total, six were submitted to surgery, three of each group, In the SCE group, patients submitted to surgery in media waited 12 hours from arrival to diagnosis without any non-therapeutic surgeries, The remaining 30 patients of this group were discharged from hospital after 24 hours of observation, In the CT group, three patients showed alteration at CT and were submitted to laparotomy, one non-therapeutic, The others were discharged from hospital after 24 hours of observation, Abdominal computer tomography had a positive predictive value (PPV) of $67 \%$ and negative predictive value (NPV) of $100 \%$, with $96 \%$ of accuracy, Isolated serial clinical exam showed PPV and NPV of $100 \%$ and $100 \%$ of accuracy. Conclusion: selective management of anterior abdominal stabs is safe, when a rigorous selection of patients is observed, Isolated serial clinical exam may be performed without computer tomography, without increase of hospitalization time or morbidity, reducing costs, exposure to radiation, mortality and morbidity and non-therapeutic laparotomies.
\end{abstract}

Keywords: Tomography, Emission-Computed. Wounds, Stab. Abdomen. Physical Examination.

\section{INTRODUCTION}

A bdominal penetrating wounds are frequently attended at trauma centers, in special due to urban violence and suicide attempts'. They include stab wounds, and the abdomen is one of the most usual inflicted location². Management of patients with anterior abdominal stab wounds is controversial, particularly of those without any signs that could justify immediate surgery (peritonitis, hemodynamic instability). In the present, selective management is recommended by several scientific publications and it is adopted by most trauma centers. The safest protocol to improve diagnostic exams efficiency, minimize costs and reduce collateral effects is still debated in literature ${ }^{3-11}$. The goal, in special of diagnosis, is to recognize if there is abdominal penetration, and, if positive, if there is any lesion of an intra-abdominal structure. Diagnostic peritoneal wash-out, FAST, video-laparoscopy and computer tomography (CT) may be used for diagnostic management of these patients, with different sensitivities and specificities ${ }^{9,12,13}$. Abdominal CT, frequently used in trauma, have good results according to literature, and is part of initial exams of several protocols. However, CT has risks related to contrast use and radiation exposure, with direct and indirect costs ${ }^{14}$. Another possible initial management is serial clinical examination (SCE) without image exams. Some authors believe that isolated SCE may increase diagnosis of unnoticed lesions that could lead to complications. Current literature has shown that

1 - Hospital de Pronto Socorro de Porto Alegre, Serviço de Cirurgia do Trauma, Porto Alegre, RS, Brasil. 2.Universidade Federal do Rio Grande do Sul, Programa de Pós-Graduação em Medicina: Ciências Cirúrgicas, Porto Alegre, RS, Brasil. 
abdominal CT and SCE among all have the highest reliability and performance ${ }^{5}$. The objective of the present study was to compare these two diagnostic methods in the management of anterior abdominal stab wounds.

\section{METHODS}

Prospective randomized clinical study of a simple random sample of patients attended at Emergency Room of Hospital de Porto Alegre, a referral trauma center of the State of Rio Grande do Sul, Brazil. Supervision and academic support were provided by the Surgical Medical Post-Graduation Department of Federal University of Rio Grande do Sul. Patients were selected from July 2011 to February 2015.

The study was approved by the Ethical Committee of Municipal Health Secretary of Porto Alegre, under the number 001.026184.11.7, in accordance to resolutions CNS 196/96, 251/97 and 292/99 of the National Health Council/National Ethics Research Council/ National Health Surveillance Agency.

In order for the patients to be included in the study, they should have been subjected to only one anterior abdominal stab wound, with hemodynamic stability and no diffuse peritoneal irritation. They were also selected if presented only pain at the site of stab and proximities. They should had 16 to 80 years old. Obligatorily Glasgow Coma Scale should be $\geq 12$, and patients with clinical signs of alcohol or drug abuse were also selected if met the coma Glasgow scale criteria. Patients could present stabs in other locations, such as thorax, extremities, head, neck or perineum, as long as such wounds did not need immediate surgery. During observation time, if there was need of surgery of other body locals, patients were excluded. Patients with previous abdominal surgery were not included in the study; patients with unquestionable need of immediate surgery, that did not meet the inclusion criteria or patients with evisceration were also excluded.

For topography analysis of anterior abdominal wall, the region was divided in four quadrants. Anterior abdominal wall was superiorly delimited by the inferior border of bilateral last costal arch, inferiorly by inguinal ligaments and pubic symphysis and laterally by right and left medium axillary line. Wound exploration included local antisepsis, placement of sterile surgical dressings, local anesthesia and digital exploration or with the aid of anatomic forceps. Abdominal cavity was considered open when it was observed violation of aponeurosis. In dubious cases (abdominal penetration) the patient was included, since in these cases it is important to observe and follow-up the patient.

After met inclusion criteria, patients were randomized by simple draw in two groups. The first group (CT group) was submitted to abdominal computer tomography with the use of intravenous contrast. In the presence of free liquid without lesion of major viscera, pneumoperitoneum, intestinal wall thickening, discontinuity of abdominal wall, retro-pneumoperitoneum or mesenteric or retroperitoneal hematoma, the patient was referred to surgery (exploratory laparotomy). Otherwise, patients were observed for 24 hours, without intake of any oral food and clinically examined every six hours. The other group (SCE) was clinically observed without any further image or laboratorial exams. Every six hours, the patient was physically examined (particularly the abdomen), including mucosa and vital signs, preferably by the same observer. If, in any group, any patient during follow up observation time presented any alteration of physical exam or vital signs (such as peritoneal irritation, hemodynamic instability, tachycardia, tachypnea or axillary temperature $=37.8^{\circ} \mathrm{C}$ ) the medical team was authorized to operate or to perform CT or laboratorial exams, in order to elucidate the diagnosis. All patients were ambulatorily attended 15 days after discharge from hospital.

CTs were performed by a helical 64-channel tomography; routine exam included a pre-contrast phase, and, following contrast injection, arterial, venous and late phases; slices were standardized as of $2 \mathrm{~mm}$. All CT scans were analyzed and validated by a radiologist and revised by the on-call surgical team, including one surgeon and two residents of the Trauma and General Surgeries Departments. Patient was follow-up during hospitalization by the same team of residents, with supervision of the attending surgeon, or, eventually, by the next day on-call surgeon.

All patients or relatives before randomization were informed and signed an informed consent term. In case of refusal, patient was not included and received 
treatment according to the recommendations of the attending surgeon.

Quantitative variables used to compare both groups (in order to verify homogeneity) included: age, hospitalization time, Glasgow coma scale, RTS (Revised Trauma Score), and TRISS (Trauma and Injury Severity Score). Categorical variables (with the same objective) included: sex, abdominal lesion topography, presence of extra-abdominal lesions, comorbidities and laparotomy performed. For categorical variables analysis, it was used the chi-square test or Fisher exact test. For quantitative variables analysis, it was used the Student t test for those with normal distribution (according to Kolmogorc-Smirnov test) and Mann-Whitney-Wilcoxon for those when it was not possible to assume a normal distribution. $\mathrm{P}=0.05$ was considered statistical significant. Sensitivity and specificity were determined by Fisher exact test, using the presence of lesion during surgical laparotomy as the gold standard parameter.

\section{RESULTS}

During the studied period, 547 patients with penetrating abdominal wounds were studied, 246 (45\%) with stab wounds. 66 patients met the inclusion criteria and were included in the study, 33 at each group. Of total, $87.9 \%$ (88) were male. Medium age was 33.2 years $(S D=13.0)$. Medium hospitalization time was 3.4 days ( $S D=7.8)$ and median was 1.0 day (1.0/2.0). Topography analysis of anterior abdominal wall divided the region in four quadrants. There were 20 wounds in superior right quadrant, 18 wounds in superior left quadrant, seven wounds in right inferior quadrant and 21 wounds in left inferior quadrant. In total, 50 patients (75.8\%) presented only lesions at abdomen, without any associated lesion in other topography. Most common lesions were at extremities (7 patients) and thorax (7 patients) (10.6\%). Glasgow coma scale score was in media 15 (SD=0.3). Revised Trauma Score (RTS) had the highest value in all sample and Trauma and Injury Severity Score medium was 0.99 (SD=0.002). Table 1 shows the demographic and clinical characteristics, proving homogeneity of groups.

Of the total, six patients $(9.1 \%)$ were submitted to laparotomy, three of each group. Table 2 shows the lesions found during laparotomy. One patient of SCE group submitted to laparotomy developed a peritoneal cavity abscess. Patients submitted to surgery of CT group included one with peritonitis and evisceration as intra-abdominal complications. All complications are described at table 3.

In the patients submitted to surgery of SCE group, medium time from initial consultation to diagnosis of the need of surgery was 12 hours (SD=6.0). In this group there were no non-therapeutic laparotomies. The 30 patients of this group that were not submitted to surgery were discharged from hospital after a minimum period of 24 hours of observation, and had no complications. In the CT group, three patients showed alterations at CT and were submitted to laparotomy. In this group, there was one non-therapeutic laparotomy (CT scan showed free liquid at abdominal cavity without lesion of major viscera). The 30 patients of this group that were not operated were discharged from hospital after a minimum period of observation of 24 hours, without complications.

CT sensitivity as initial diagnostic method was $100 \%$; specificity was $96.7 \%$, positive predictive value was $67 \%$ and negative predictive value was $100 \%$, accuracy was $96 \%$. SCE showed sensitivity and specificity of $100 \%, 100 \%$ of accuracy (Table 4 ).

\section{DISCUSSION}

Non-surgical selective management of penetrating abdominal stab wounds has changed over the last years. A classical paper published by Shaftan ${ }^{15}$, in 1960, proposed a new era of management of abdominal trauma. Some publications show that indication of systematic laparotomy for patients with penetrating stab abdominal wounds can lead to a non-therapeutic laparotomy rate of $71 \%$ to $82 \%{ }^{16,17}$. Literature affirms that selective management is adequate and save, as long as rigid criteria of selection of patients is observed and performed at a referral trauma center ${ }^{18}$. Many surgeons in several countries adopt this treatment ${ }^{19,20}$ and it is performed at Emergency Room of Hospital de Porto Alegre for many years. However, definition of the best way to treat anterior abdominal wall stab wounds, particularly at first moment, is still not well stablished, 
Table 1. Clinical and demographic characteristics.

\begin{tabular}{|c|c|c|c|}
\hline & SCE group $(n=33)$ & CT group $(n=33)$ & $\mathrm{P}^{\mathrm{c}}$ \\
\hline Age (years) ${ }^{a}$ & $34.7(12.7)$ & $31.6(13.4)$ & 0.243 \\
\hline Gender (\%) & & & 0.451 \\
\hline Male & $28(84.8)$ & $30(90.9)$ & \\
\hline Female & $5(15.2)$ & $3(9.1)$ & \\
\hline Hospitalization (days) ${ }^{b}$ & $1.0(1.0 / 2.0)$ & $1.0(1.0 / 2.0)$ & 0.915 \\
\hline Glasgow (admission)a $^{a}$ & $15(0.2)$ & $15(0.3)$ & 0.957 \\
\hline RTS $^{\mathrm{a}}$ & $7.6(0.0)$ & $7.6(0.0)$ & 1.000 \\
\hline TRISSa & $99(0.0)$ & $99(0.0)$ & 1.000 \\
\hline Topography of lesion at abdominal wall (\%) & & & 0.490 \\
\hline RSQ & $11(33.3)$ & $9(27.3)$ & \\
\hline LSQ & $7(21.2)$ & $11(33.3)$ & \\
\hline RIQ & $5(15.2)$ & $2(6.1)$ & \\
\hline LEQ & $10(30.3)$ & $11(33.3)$ & \\
\hline Extra-abdominal lesion (\%) & $6(18.2)$ & $10(30.3)$ & 0.251 \\
\hline Comorbidities (\%) & $17(51.5)$ & $17(51.5)$ & 1.000 \\
\hline Laparotomy (\%) & $3(9.1)$ & $3(9.1)$ & 1.000 \\
\hline
\end{tabular}

SCE: serial clinical exam, CT: computer tomography, a Medium (Standard Deviation); ${ }^{b}$ Median (interval 25/75), 'Chi-square test or Fisher Exact test for categorical variables; t Student test and Mann-Whitney-Wilcoxon test for quantitative variables; RTS= Revised Trauma Score; TRISS= Trauma and Injury Severity Score; RSQ= right superior quadrant; $\mathrm{LSQ}=$ left superior quadrant; $\mathrm{RIQ}=$ right inferior quadrant; $\mathrm{LIQ}=$ left inferior quadrant.

Table 2. Lesions found at laparotomies.

\begin{tabular}{lcc}
\hline Lesions (organs) & SCE group & CT group \\
\hline Duodenum & 1 & 0 \\
Liver & 2 & 1 \\
Small intestine & 0 & 1 \\
Gallbladder & 0 & 1 \\
\hline
\end{tabular}

$\mathrm{SCE}=$ serial clinical exam; CT=computer tomography.

Table 3. Complications.

\begin{tabular}{lccc}
\hline Complications & $\begin{array}{c}\text { SCE group } \\
\mathrm{n}(\%)\end{array}$ & $\begin{array}{c}\text { CT group } \\
\mathrm{n}(\%)\end{array}$ & $\mathrm{Pa}$ \\
\hline Infection & $4(12.1)$ & $3(9.1)$ & 0.689 \\
Abdominal & $1(3.0)$ & $1(3.0)$ & 1.000 \\
Thoracic & $2(6.1)$ & $2(6.1)$ & 1.000 \\
Other & 0 & $1(3.0)$ & 0.314 \\
\hline
\end{tabular}

$\mathrm{SCE}=$ serial clinical exam; $\mathrm{CT}=$ computer tomography; ${ }^{a}$ Chi-square test.

Table 4. Performance of serial clinical exam (SCE) and computer tomography $(C T)$.

\begin{tabular}{lcc}
\hline & $\begin{array}{c}\text { SCE group } \\
(\mathrm{n}=33)\end{array}$ & $\begin{array}{c}\text { CT group } \\
(\mathrm{n}=33)\end{array}$ \\
\hline Sensitivity (\%) & 100 & 100 \\
Specificity (\%) & 100 & 96.7 \\
PPV (\%) & 100 & 67.0 \\
NPV (\%) & 100 & 100 \\
Accuracy (\%) & 100 & 96.0 \\
\hline
\end{tabular}

PPV: positive predictive value; NPV: negative predictive value. with many different approaches.

Abdominal $\mathrm{CT}$, frequently used at trauma, has excellent results according to literature, and is included initially in many protocols ${ }^{21}$. The advantages are to highlight intraperitoneal and retroperitoneal lesions, as well as, in some circumstances, determinate the grade of penetration of abdominal wall. CT disadvantages are related to the use of intravenous contrast and possible adverse reactions, radiation and incapacity to detect diaphragmatic lesions or, occasionally, of small lesions of hollow viscera ${ }^{14}$. Berardoni et al. ${ }^{22}$ studied 98 patients with inclusion criteria for non-surgical management of anterior abdominal stab wounds and verified that CT had a sensitivity of $93 \%$, specificity of $93 \%$, predictive positive value of $70 \%$ and negative predictive value of $99 \%$. Salim et al. ${ }^{21}$ published a retrospective observational study in order to verify validity of CT in patients with stab wound at anterior abdominal wall and concluded that CT must be associated with physical exam for better diagnostic performance. Another paper by Lee et al. ${ }^{13}$, in 2015, analyzed 108 patients with abdominal stab wounds submitted to abdominal CT, and in all, CT was positive. Authors concluded that $C T$, when positive, has high diagnostic value. However, when negative, does not rule de- 
finitively out the possibility of abdominal lesion.

In the present work, abdominal CT had a predictive positive value of $67 \%$ and negative of $100 \%$. When we analyze these data, we verify that all patients with negative CT were not operated and were discharged from hospital. In relation to the three patients with positive CT and indication to surgery, two had lesions and one not, only the presence of blood in small quantity in the abdomen. In that case, CT showed free liquid without lesion of major viscera. Such findings proved that CT sensitivity for positive patients was very good, but with some lack of specificity, that is, capacity to detect truly negative patients.

SCE is a diagnostic and semiological method that includes a systematic sequential anamnesis and physical exam, with defined intervals, to detect early alterations related to surgical lesion ${ }^{5}$. Ertekin el al. ${ }^{23}$ analyzed 117 patients with penetrating stab abdominal trauma and $79 \%$ were successfully treated without surgery by SCE, that included physical exam, leucogram and body temperature every four hours. The maximum period after which the patients presented symptoms was 20 hours. The present work showed that there are no difference of complications among patients initially operated and those who needed surgery after appearance of symptoms. Van Haarst et al. ${ }^{24}$ in a retrospective work of ten years analyzed efficiency of SCE in 370 consecutive patients with penetrating abdominal trauma (322 with stab wounds) and verified an important reduction of non-therapeutic laparotomies, from $24 \%$ to zero, in the last year of study, by using SCE. It is important to emphasize that there was no increase of morbidity and mortality in the operated group after beginning of symptoms. Clarke et al. ${ }^{25}$ emphasized the possibility of selective management with SCE, but highlighted that lesions at the epigastric and right hypochondrium regions should be cautiously evaluated and with higher attention. Alzamel et al. ${ }^{26}$, in another work, investigated what period after which the patients with stab abdominal wounds could be discharged from hospital. They showed that the maximum period of observation for appearance of symptoms was 12 hours. Most patients with penetrating abdominal wound not submitted to early surgery could be discharged from hospital after 24 hours of observation, as long as they did not show any alteration of physical, image or laboratorial exams ${ }^{5,27}$

In the present work, among 33 patients randomized for SCE, only three were submitted to surgery and beginning of symptoms occurred at most in 18 hours. Those 30 patients not submitted to surgery were discharged from hospital without complications. It is important to emphasize that clinical exam included only anamnesis and physical exam, without laboratory exams. SCE had excellent capacity to detect patients with abdominal lesion before 24 hours, period in which post-operatory complications are small. It is important also to emphasize that correct selection of patients for SCE by strict criteria lowers very much the possibility of undetected intra-abdominal lesion at initial physical exam. When SCE and CT isolated are compared, management results were very similar in terms of sensitivity, specificity, predictive values and accuracy (Table 4).

Variability of protocols show that exact definition of management of these patients is still missing $3,4,6-11$. Most protocols propose wound exploration in hemodynamically stable patients without peritoneal signs, followed by early laparotomy, SCE, FAST or CT if peritoneal violation is present or in doubt cases. SCE proved to be a reliable method in most studies, identifying patients that needed surgery within 24 hours after trauma, ruling out, efficiently, patients without the need for surgery.

Non-surgical selective management of patients with anterior abdominal wall stab wounds must be based in strict criteria: patient must be hemodynamically stable, without peritoneal irritation, with score of 12 or more at the Glasgow coma scale, and without no surgical indication in any other surgical compartment. If these prerequisites are met, the chances of late lesion lowers very much and the patient may be submitted to isolated SCE without prejudice to morbidity, lowering costs, exposure to radiation, adverse effects of intravenous contrast and non-therapeutic laparotomies.

\section{ACKNOWLEDGEMENT}

We particularly thank nurse Márcia Koja Breigeiron for her invaluable help during the several phases of the study. 


\title{
R E S U M O
}

\begin{abstract}
Objetivo: comparar tomografia computadorizada de abdome (TC) com exame clínico seriado (ECS) isolado na condução de ferimentos por arma branca na região anterior do abdome. Métodos: estudo prospectivo, randomizado, realizado no Hospital de Pronto Socorro de Porto Alegre em que pacientes com ferimentos por arma branca na parede anterior do abdome, sem indicação de laparotomia imediata, foram divididos em dois grupos: grupo TC e grupo ECS, No grupo ECS, os pacientes eram observados com exame clínico seriado de 6/6h, No grupo TC, eram submetidos à tomografia computadorizada de abdome após a avaliação inicial. Resultados: dos 66 pacientes estudados, 33 foram selecionados para cada grupo, Do total, seis foram submetidos à cirurgia, três de cada grupo, No grupo ECS, pacientes submetidos à cirurgia tiveram média de $12 \mathrm{~h}$ entre a chegada e o diagnóstico, sem laparotomias não terapêuticas, Os 30 pacientes restantes deste grupo receberam alta após $24 \mathrm{~h}$ de observação, No grupo TC, três pacientes apresentaram alterações na TC e foram submetidos à laparotomia, uma não terapêutica, Os demais receberam alta após observação de 24h, A tomografia computadorizada de abdome apresentou valor preditivo positivo (VPP) de 67\% e valor preditivo negativo (VPN) de 100\%, com acurácia de $96 \%$, O exame clínico seriado isolado, teve VPP e VPN de 100\%, com acurácia de 100\%. Conclusão: o manejo seletivo para ferimentos por arma branca na parede abdominal anterior é seguro, caso obedeça a uma seleção rigorosa dos pacientes, O exame clínico seriado isolado pode ser realizado sem a necessidade de tomografia, sem aumento do tempo de internação ou da morbidade, o que reduz custos, exposição à radiação, morbimortalidade e laparotomias não terapêuticas.
\end{abstract}

Descritores: Tomografia Computadorizada de Emissão. Ferimentos Perfurantes. Abdome. Exame Físico.

\section{REFERENCES}

1. Venara A, Jousset $N$, Airagnes G Jr, Arnaud JP, Rouge-Maillart $C$. Abdominal stab wounds: selfinflicted wounds versus assault wounds. J Forensic Leg Med. 2013;20(4):270-3.

2. Kharytaniuk N, Bass GA, Salih A, Twyford $M$, $\mathrm{O}^{\prime}$ Conor $\mathrm{E}$, Collins $\mathrm{N}$, et al. Penetrating stab injuries at a single urban unit: are we missing the point? Ir J Med Sci. 2015;184(2):449-55.

3. Biffl WL, Kaups KL, Cothren CC, Brasel KJ, Dicker RA, Bullard MK, et al. Management of patients with anterior abdominal stab wounds: a Western Trauma Association multicenter trial. J Trauma. 2009;66(5):1294-301.

4. Biffl WL, Moore EE, Management guidelines for penetrating abdominal trauma. Curr Opin Crit Care. 2010;16(6):609-17.

5. Como JJ, Bokhari F, Chiu WC, Duane TM, Holevar MR, Tandoh MA, et al. Practice management guidelines for selective nonoperative management of penetrating abdominal trauma. J Trauma. 2010;68(3):721-33.

6. Biffl WL, Kaups KL, Pham TN, Rowell SE, Jurkovich GJ, Burlew CC, et al. Validating the Western Trauma Association algorithm for managing patients with anterior abdominal stab wounds: a Western Trauma Association multicenter trial. J Trauma. 2011;71(6):1494-502.

7. Paydar S, Salahi R, Izadifard F, Jaafari Z, Abbasi HR, Eshraghian $A$, et al. Comparison of conservative management and laparotomy in the management of stable patients with abdominal stab wound. Am J Emerg Med. 2012;30(7):1146-51.

8. Omari A, Bani-Yaseen M, Khammash M, Qasaimeh G, Eqab F, Jaddou H. Patterns of anterior abdominal stab wounds and their management at Princess Basma teaching hospital North of Jordan. World J Surg. 2013;37(5):1162-8.

9. Sumislawski JJ, Zarzaur BL, Paulus EM, Sharpe JP, Savage SA, Nawaf CB, et al. Diagnostic laparoscopy after anterior abdominal stab wounds: worth another look? J Trauma Acute Care Surg. 2013;75(6):1013-7; discussion 1017-8.

10. Rezende Neto JB, Vieira Jr HM, Rodrigues BDL, Rizoli S, Nascimento B, Fraga GP. Management of stab wounds to the anterior abdominal wall. Rev Col Bras Cir. 2014;41(1):75-9.

11. Biffl $W L$, Leppaniemi $A$. Management guidelines for penetrating abdominal trauma. World J Surg. 2015;39(6):1373-80.

12. Quinn AC, Sinert R. What is the utility of the Focused Assessment with Sonography in Trauma (FAST) exam in penetrating torso trauma? Injury. 2011;42(5):482-7.

13. Lee GJ, Son G, Yu BC, Lee JN, Chung M. Efficacy of computed tomography for abdominal stab wounds: a single institutional analysis. Eur J Trauma Emerg Surg. 2015;41(1):69-74.

14. Brenner DJ, Hall EJ. Current concepts - Computed tomography - An increasing source of radiation exposure. New Eng J Med. 2007;357(22): 2277-84. 
15. Shaftan GW. Indications for operation in abdominal trauma. Amer J Surg. 1960,99(5):657-64.

16. Sanei B, Mahmoudieh M, Talebzadeh H, Shahmiri SS, Aghaei Z. Do patients with penetrating abdominal stab wounds require laparotomy? Arch Trauma Res. 2013;2(1):21-5.

17. Murry JS, Hoang DM, Ashragian S, Liou DZ, Barmparas G, Chung Ret al. Selective nonoperative management of abdominal stab wounds. Am Surg. 2015;81(10):1034-8.

18. Hope WW, Smith ST, Medieros B, Hughes KM, Kotwall CA, Clancy TV. Non-operative management in penetrating abdominal trauma: is it feasible at a Level II trauma center? J Emerg Med. 2012;43(1):190-5.

19. Demetriades $D$, Hadjizacharia $P$, Constantinou C, Brown C, Inaba K, Rhee $P$, et al. Selective nonoperative management of penetrating abdominal solid organ injuries. Ann Surg. 2006;244(4):620-8.

20. Jansen JO, Inaba K, Rizoli SB, Boffard KD, Demetriades $D$. Selective non-operative management of penetrating abdominal injury in Great Britain and Ireland: survey of practice. Injury. 2012;43(11):1799-804.

21. Salim A, Sangthong B, Martin M, Brown C, Plurad $D$, Inaba $K$, et al. Use of computed tomography in anterior abdominal stab wounds: results of a prospective study. Arch Surg. 2006;141(8):745-50; discussion 750-2.

22. Berardoni NE, Kopelman TR, O'Neill PJ, August DL, Vail SJ, Pieri PG, et al. Use of computed tomography in the initial evaluation of anterior abdominal stab wounds. Am J Surg. 2011;202(6):690-5; discussion 695-6.

23. Ertekin C, Yanar H, Taviloglu K, Güloglu R, Alimoglu O. Unnecessary laparotomy by using physical examination and different diagnostic modalities for penetrating abdominal stab wounds. Emerg Med J. 2005;22(11):790-4.

24. van Haarst EP, van Bezooijen BP, Coene PPL, Luitse JS. The efficacy of serial physical examination in penetrating abdominal trauma. Injury. 1999;30(9):599-604.

25. Clarke DL, Allorto NL, Thomson SR. An audit of failed non-operative management of abdominal stab wounds. Injury. 2010;41(5):488-91.

26. Alzamel HA, Cohn SM. When is it safe to discharge asymptomatic patients with abdominal stab wounds? J Trauma. 2005;58(3):523-5.

27. Martínez Cl, Sancho IJ, Climent AM, Membrilla FE, Pons FM, Guzmán AJ, et al. A study of the predictive value of the primary review and complementary examinations in assessing the need for surgery in patients with stab wounds in the torso. Cir Esp. 2013;91(7):450-6.

Received in: 23/08/2017

Accepted for publication: 17/09/2017

Conflict of interest: none.

Source of funding: none.

\section{Mailing address:}

Ricardo Breigeiron

E-mail: rbreigeiron@gmail.com / carloscorso04@gmail.com 